\title{
Associations of Estimated Glomerular Filtration Rate with All-Cause Mortality and Cardiovascular Mortality in Patients with Diabetic Foot Osteomyelitis
}

\author{
Jianhao Huang $\mathbb{D}^{1}{ }^{1, *}$ \\ Weiwei $\mathrm{Li}^{2, *}$ \\ Suosu Wei iD $^{3, *}$ \\ Xing Zhou (D) \\ Yuechou Nong' \\ Jingxia Sun' \\ Zhenwei Zhai ${ }^{1}$ \\ Wensheng Lu (ID) \\ 'Department of Endocrinology and \\ Metabolism, Guangxi Academy of Medical \\ Sciences and the People's Hospital of \\ Guangxi Zhuang Autonomous Region, \\ Nanning, Guangxi, 53002I, People's \\ Republic of China; ${ }^{2}$ The Office of \\ Guangxi Academy of Medical Sciences \\ and the People's Hospital of Guangxi \\ Zhuang Autonomous Region, Nanning, \\ Guangxi, 53002I, People's Republic of \\ China; ${ }^{3}$ Editorial Board of Chinese \\ Journal of New Clinical Medicine, \\ Guangxi Academy of Medical Sciences \\ and the People's Hospital of Guangxi \\ Zhuang Autonomous Region, Nanning, \\ Guangxi, 53002I, People's Republic of \\ China
}

*These authors contributed equally to this work

\begin{abstract}
Aim: The purpose of this study was to explore the association between estimated glomerular filtration rate (eGFR) and clinical outcomes in patients with diabetic foot osteomyelitis (DFO).

Methods: This was a retrospective observational study. A total of 199 patients with DFO were recruited and divided into three groups by eGFR: normal kidney function group (eGFR $\geq 90$ ), mildly decreased kidney function group (eGFR 60-89) and moderately to severely decreased kidney function group $(\mathrm{eGFR}<60)$. The patients were followed-up for a median of 36 months, and the study outcomes were all-cause mortality and major cardiovascular adverse events (MACE). Cox proportional hazard models were used to assess the association between eGFR and the outcomes, and a stratified analysis by sex was conducted.

Results: During follow-up, all-cause mortality occurred in 51 (25.63\%) patients among 199 participants, $54(28.72 \%)$ had MACE in 188 participants and $26(48.15 \%)$ of them died. After fully adjusting for potential confounders, compared to eGFR $<90 \mathrm{~mL} / \mathrm{min} / 1.73 \mathrm{~m}^{2}$, eGFR $\geq 90 \mathrm{~mL} / \mathrm{min} / 1.73 \mathrm{~m}^{2}$ had lower incidence of all-cause mortality $(\mathrm{HR}=0.43,95 \% \mathrm{CI}$ : $0.22-0.85 ; P=0.015)$ and MACE $(\mathrm{HR}=0.51,95 \% \mathrm{CI}: 0.27-0.96 ; P=0.038)$. Additionally, compared to eGFR $<90 \mathrm{~mL} / \mathrm{min} / 1.73 \mathrm{~m}^{2}$, eGFR $\geq 90 \mathrm{~mL} / \mathrm{min} / 1.73 \mathrm{~m}^{2}$ was independently associated with decreased risk of all-cause mortality $(\mathrm{HR}=0.33 ; 95 \%$ CI $0.14-0.76$, $P=0.010)$ and MACE $(\mathrm{HR}=0.27 ; 95 \%$ CI $0.11-0.65, P=0.004)$ in male, but not in female. Conclusion: In conclusion, decreased eGFR is a risk factor for all-cause mortality and MACE in individuals with DFO. Additionally, male with decreased eGFR had a higher risk of all-cause mortality and MACE, but female did not.
\end{abstract}

Keywords: diabetic foot osteomyelitis, estimated glomerular filtration rate, prognosis

\section{Introduction}

Diabetic foot osteomyelitis (DFO) is mostly caused by the contiguous spread of foot infection to adjacent soft tissue and eventually to bone. ${ }^{1}$ At present, the number of diabetes is increasing yearly worldwide and the prevalence of diabetes in China increased to $11.2 \% .^{2}$ About $15-25 \%$ of diabetic patients develop diabetic foot disease during the progression of the disease. ${ }^{3}$ Even though the prevalence and mortality differ between countries, ${ }^{4}$ recent studies, which come from China have shown that the annual mortality rate of Chinese patients with diabetic foot disease is $14.40 \%{ }^{5}$ and the 5-year mortality rate is about $50 \%{ }^{6}$ Among patients with diabetic 
foot disease, more than $60 \%$ have ulcer with infection and DFO patients often have more complicated ulcers and more extensive infection. ${ }^{7}$

Chronic complications of diabetes include microvascular and macrovascular complications. The occurrence and development of diabetic foot disease are closely related to diabetic lower extremity arterial disease and diabetic peripheral vascular disease (PVD). ${ }^{8}$ Therefore, clinically, diabetic foot disease usually does not exist in a single form. Diabetic foot disease is complicated with multiple complications and multiple target organ damage can result in increased medical expenditures, decline in quality of life, ${ }^{9}$ difficulty in wound healing and recurrence of foot ulcers, so it has become a problem ${ }^{10}$ and a research hotspot in the medical field.

Diabetic nephropathy is a common chronic complication combined with diabetic foot disease. Studies ${ }^{11}$ have shown that chronic kidney disease is related to the risk of cardiovascular events and all-cause mortality in diabetic patients. The decline in estimated glomerular filtration rate (eGFR) and end-stage renal disease (ESRD) is related to the survival time of diabetic foot disease. ${ }^{12}$ Among patients with diabetic foot ulcers, patients with DFO tend to have more severe infections and more complicated conditions than those without osteomyelitis. However, few studies have reported on the prognosis of DFO and the value of eGFR as an evaluation index of kidney function in DFO patients. Moreover, there is also no research to observe the relationship between eGFR and the prognosis of DFO and further investigate the difference between male and female in clinical outcomes by eGFR in DFO patients. To this end, we propose a hypothesis: eGFR levels are associated with the clinical outcomes of DFO patients, and decreased eGFR may be a risk factor for all-cause mortality and major cardiovascular adverse events (MACE) in DFO patients. We aim to investigate the associations of eGFR with all-cause mortality and MACE in 199 DFO patients and explore the differences between sexes.

\section{Methods}

\section{Subjects}

From June 2015 to June 2017, a total of 199 patients with DFO who were hospitalized in the Department of Endocrinology, Guangxi Academy of Medical Sciences and the People's Hospital of Guangxi Zhuang Autonomous Region were selected. The following inclusion criteria were utilized: (1) diabetes was diagnosed in accordance with criteria established by the World Health Organization (WHO) in 1999; ${ }^{13}$ (2) DFO was diagnosed according to the criteria established by the World Health Organization International Working Group on Diabetic Foot (IWGDF). ${ }^{14}$ The exclusion criteria were as follows: (1) non-diabetic foot ulcers such as venous ulcers caused by varicose veins, ${ }^{15}$ tophus ulcers and bedsores caused by prolonged bed rest; (2) patients with long-term use of glucocorticoids or immunosuppressants; (3) patients were lost to follow-up and had incomplete medical records or insufficient follow-up time. Written informed consent was provided by all patients prior to undergoing any studyrelated procedures. This study was conducted in accordance with the Declaration of Helsinki and approved by the Ethics Committee of the People's Hospital of Guangxi Zhuang Autonomous Region.

\section{Definitions and Impact Factors}

Venous blood samples were taken after 8 hours of overnight fasting. According to the 2012 Kidney Disease Improving Global Outcomes (KDIGO) guidelines, ${ }^{16}$ baseline eGFR was categorized into three groups: normal kidney function (eGFR $\geq 90 \mathrm{~mL} / \mathrm{min} / 1.73 \mathrm{~m}^{2}$ ), mildly decreased kidney function (eGFR $=60$ to $89 \mathrm{~mL} / \mathrm{min} /$ $1.73 \mathrm{~m}^{2}$ ) and moderately-to-severely decreased kidney function $\left(\mathrm{eGFR}<60 \mathrm{~mL} / \mathrm{min} / 1.73 \mathrm{~m}^{2}\right.$ ). Meanwhile, for survival analysis, eGFR was grouped into two categories: normal kidney function (eGFR $\geq 90 \mathrm{~mL} / \mathrm{min} / 1.73 \mathrm{~m}^{2}$ ) and abnormal kidney function (eGFR $<90 \mathrm{~mL} / \mathrm{min} / 1.73 \mathrm{~m}^{2}$ ). The eGFR was calculated through MDRD equation for Chinese adults: eGFR $=175 \times($ serum creatinine $[\mathrm{mg} /$ $\mathrm{dL}])^{-1.234} \times$ age $^{-0.179} \times 0.79$ (if female). ${ }^{17}$

According to the guidelines on the diagnosis and treatment of foot infection in persons with diabetes (IWGDF 2019 update), ${ }^{14}$ we used a combination of the probe bone (PTB), inflammatory biomarkers including erythrocyte sedimentation rate (ESR), high-sensitivity C-reactive protein (hsCRP), procalcitonin (PCT), and plain X-rays to diagnose DFO and confirmed through histopathology of bone biopsy. The severity of DFO infection was classified according to the Guidelines of The International Working group on the Diabetic Foot/Infectious Diseases Society of America system (IWGDF/IDSA). ${ }^{18}$ Ischemic or non-ischemic infected wounds were classified according to the University of Texas Diabetic Wound Classification (UTDWC). ${ }^{19}$

Also, we collected other information about impact factors. The demographics include age, sex, body mass index (BMI) and smoking status. Laboratory parameters 
collected included: serum creatinine ( $\mathrm{SCr}$ ), urinary albumin-to-creatinine ratio (UCAR), glycosylated hemoglobin (HbAlc), white blood cells (WBC), hemoglobin ( $\mathrm{Hb}$ ), total cholesterol (TC), triglycerides (TG), high-density lipoprotein cholesterol (HDL-C), low-density lipoprotein cholesterol (LDL-C), apolipoprotein A1 (apoA1), apolipoprotein $\mathrm{B}$ (apoB). The medical histories of the patients were collected, including type and duration of diabetes, hypertension, coronary heart disease (CHD), cardiovascular diseases (CVD), sepsis, peripheral arterial diseases (PVD) and foot examinations (neuropathy, the degree and location of infection).

\section{Outcomes}

The outcomes of the study were all-cause mortality and MACE within three years after DFO diagnosis. Clinical outcome occurrences were obtained by the medical files in our department for outpatient or inpatient and by telephone to contact the patients or patients' families using online questionnaires. MACE was defined as cardiovascular mortality, non-fatal myocardial infarction and non-fatal stroke. $^{11}$

\section{Statistical Analyses}

Data were expressed as mean $\pm \mathrm{SD}$ or as median (quartiles) as appropriate. Categorical variables were expressed using percentages (\%). For comparisons between multiple groups, one-way ANOVA and Kruskal-Wallis rank sum tests were applied. Pearson $\chi^{2}$ test was used for categorical variables. The cumulative incidence of all-cause mortality and MACE was estimated between eGFR $<90 \mathrm{~mL} / \mathrm{min} /$ $1.73 \mathrm{~m}^{2}$ group and eGFR $\geq 90 \mathrm{~mL} / \mathrm{min} / 1.73 \mathrm{~m}^{2}$ group by using Kaplan-Meier analysis and compared by the Log rank test. Univariate Cox proportional hazard analysis was used to identify the statistically significant variables for all-cause mortality and MACE. Multivariate Cox proportional hazard analysis was then used with these statistically significant and clinically meaningful variables to investigate whether different eGFR levels are associated with allcause mortality and MACE in patients with DFO. The results were presented as hazard ratios (HRs) with 95\% confidence intervals (CIs). Cox proportional hazard analysis was performed with three different models as follows: crude model: no adjustment; model I: adjustment for age, sex, smoke and duration of diabetes; model II: adjustment for model I + SCR, CHD, hindfoot, infection, sepsis and ABI. Besides, the analyses were repeated after stratification by sex. Data analyses were performed using the SPSS
18 statistical software package (IBM Corp., Armonk, NY, USA). $P$ value $<0.05$ was considered statistically significant.

\section{Results \\ Baseline Characteristics of the Study Cohort}

A total of 199 patients with DFO were enrolled in this study. The average age was $60.19 \pm 12.50,62.81 \%$ were male. The baseline characteristics of the patients according to the baseline eGFR categories are shown in Table 1. Among the patients, 39 individuals $(71.79 \%$ male; mean age $62.62 \pm$ 13.18 years) had moderately to severely decreased kidney function, 48 individuals $(62.50 \%$ male; mean age $62.35 \pm$ 10.86 years) had mildly decreased kidney function and 112 individuals (59.82\% male; mean age $58.41 \pm 12.73$ years) had normal kidney function. At the initiation of the study, individuals with higher eGFR had lower SCr and lower UACR and were more likely to have a history of CHD. Other characteristics at baseline were similar among the three groups.

\section{The Associations Between Normal Kidney Function and Abnormal Kidney Function with the Outcomes All-Cause Mortality and MACE}

The patients were followed up for a median of 36 months (range, 2-36 months). During the follow-up period, 51 (25.63\%) individuals died in 199 patients. Data on MACE were available from 188 patients due to missing data such as early death with other causes. There were 54 (28.72\%) individuals had MACE and 26 of them died (data not shown). Among them, 18 (35.29\%) and $33(64.71 \%)$ patients died in eGFR $\geq$ $90 \mathrm{~mL} / \mathrm{min} / 1.73 \mathrm{~m}^{2}$ group and eGFR $<90 \mathrm{~mL} / \mathrm{min} /$ $1.73 \mathrm{~m}^{2}$ group, respectively; $20(37.04 \%)$ and 34 (62.96\%) patients had MACE in eGFR $\geq 90 \mathrm{~mL} / \mathrm{min} /$ $1.73 \mathrm{~m}^{2}$ group and eGFR $<90 \mathrm{~mL} / \mathrm{min} / 1.73 \mathrm{~m}^{2}$ group, respectively. The eGFR $\geq 90 \mathrm{~mL} / \mathrm{min} / 1.73 \mathrm{~m}^{2}$ group had lower rates of all-cause mortality and MACE compared to eGFR $<90 \mathrm{~mL} / \mathrm{min} / 1.73 \mathrm{~m}^{2}(P<0.05$ for both $)$. Kaplan-Meier analysis demonstrated that eGFR < $90 \mathrm{~mL} / \mathrm{min} / 1.73 \mathrm{~m}^{2}$ group showed higher incidence of the 3-year all-cause mortality and MACE than the eGFR $\geq 90 \mathrm{~mL} / \mathrm{min} / 1.73 \mathrm{~m}^{2}$ group (log rank, both $P<0.01$ ) (Figure 1). In the univariate Cox proportional-hazard analysis, 26 variables were identified that were 
Table I Baseline Characteristics of the Study Population Based on eGFR (mL/Min/I.73m²)

\begin{tabular}{|c|c|c|c|c|c|}
\hline Characteristics & All $(\mathbf{N}=199)$ & $<60(\mathrm{~N}=39)$ & $60-89(N=48)$ & $\geq 90(\mathrm{~N}=1 \mid 2)$ & $P$ \\
\hline Age, years & $60.19 \pm 12.50$ & $62.62 \pm 13.18$ & $62.35 \pm 10.86$ & $58.41 \pm 12.73$ & 0.075 \\
\hline Sex, n (\%) & & & & & $0.4 I I$ \\
\hline Female & 74 (37.19\%) & II (28.2I\%) & 18 (37.50\%) & $45(40.18 \%)$ & \\
\hline Male & 125 (62.81\%) & 28 (71.79\%) & $30(62.50 \%)$ & $67(59.82 \%)$ & \\
\hline Smoke, n (\%) & & & & & 0.373 \\
\hline No & 91 (45.73\%) & $15(38.46 \%)$ & $20(41.67 \%)$ & $56(50.00 \%)$ & \\
\hline Yes & 108 (54.27\%) & $24(61.54 \%)$ & $28(58.33 \%)$ & $56(50.00 \%)$ & \\
\hline Duration of diabetes (years) & $11.31 \pm 6.16$ & $10.38 \pm 6.46$ & $11.48 \pm 6.15$ & $11.56 \pm 6.08$ & 0.578 \\
\hline TEXAS, n (\%) & & & & & 0.787 \\
\hline $3 B$ & 96 (48.24\%) & 17 (43.59\%) & $23(47.92 \%)$ & $56(50.00 \%)$ & \\
\hline $3 \mathrm{D}$ & 103 (5I.76\%) & $22(56.41 \%)$ & $25(52.08 \%)$ & $56(50.00 \%)$ & \\
\hline \multicolumn{6}{|l|}{ Laboratory parameters } \\
\hline $\mathrm{SCr}$, umol/L & $78.71 \pm 38.69$ & $122.40 \pm 59.73$ & $83.97 \pm 17.82$ & $61.25 \pm 18.00$ & $<0.001$ \\
\hline eGFR, $\mathrm{mL} / \mathrm{min} \cdot 1.73 \mathrm{~m}^{2}$ & $92.43 \pm 32.03$ & $48.56 \pm 7.20$ & $76.27 \pm 7.10$ & $1 \mid 4.64 \pm 22.46$ & $<0.001$ \\
\hline UACR, mg/g & $26.79(17.56-106.73)$ & $353.26(26.49-434.93)$ & $28.99(18.29-109.75)$ & $25.05(16.69-61.40)$ & $<0.001$ \\
\hline HbAlc, \% & $8.88 \pm 2.05$ & $8.88 \pm 1.96$ & $8.41 \pm 2.26$ & $9.08 \pm 1.97$ & 0.171 \\
\hline WBC, $\times 10^{9} / \mathrm{L}$ & $|1.4| \pm 2.84$ & $11.82 \pm 2.67$ & $10.79 \pm 2.98$ & $11.53 \pm 2.83$ & 0.195 \\
\hline $\mathrm{Hb}, \mathrm{g} / \mathrm{L}$ & $117.21 \pm 20.37$ & $119.63 \pm 17.11$ & $117.83 \pm 19.56$ & $116.10 \pm 21.78$ & 0.631 \\
\hline $\mathrm{TC}, \mathrm{mmol} / \mathrm{L}$ & $4.69 \pm 1.76$ & $4.57 \pm 1.86$ & $4.47 \pm 1.90$ & $4.82 \pm 1.66$ & $0.45 I$ \\
\hline $\mathrm{TG}, \mathrm{mmol} / \mathrm{L}$ & $2.06 \pm 0.56$ & $2.22 \pm 0.57$ & $2.03 \pm 0.50$ & $2.01 \pm 0.57$ & 0.119 \\
\hline HDL-C, $\mathrm{mmol} / \mathrm{L}$ & $1.16 \pm 0.38$ & $1.19 \pm 0.34$ & $1.13 \pm 0.41$ & $1.17 \pm 0.38$ & 0.780 \\
\hline LDL-C, mmol/L & $2.77 \pm 0.93$ & $2.77 \pm 0.88$ & $2.71 \pm 1.01$ & $2.80 \pm 0.93$ & 0.859 \\
\hline apoAI, g/L & $1.20 \pm 0.26$ & $1.17 \pm 0.24$ & $1.23 \pm 0.28$ & $1.19 \pm 0.26$ & 0.606 \\
\hline apoB, g/L & $0.96 \pm 0.25$ & $1.02 \pm 0.22$ & $0.94 \pm 0.28$ & $0.94 \pm 0.24$ & 0.228 \\
\hline$A B I$ & $0.87 \pm 0.36$ & $0.80 \pm 0.40$ & $0.84 \pm 0.31$ & $0.90 \pm 0.36$ & 0.244 \\
\hline \multicolumn{6}{|l|}{ Comorbidities } \\
\hline T2DM, n (\%) & & & & & $0.56 \mathrm{I}$ \\
\hline No & $9(4.52 \%)$ & $3(7.69 \%)$ & $2(4.17 \%)$ & $4(3.57 \%)$ & \\
\hline Yes & 190 (95.48\%) & $36(92.31 \%)$ & 46 (95.83\%) & 108 (96.43\%) & \\
\hline Hypertension, n (\%) & & & & & 0.746 \\
\hline No & $36(18.09 \%)$ & $8(20.51 \%)$ & 7 (14.58\%) & 21 (18.75\%) & \\
\hline Yes & 163 (81.91\%) & 31 (79.49\%) & $4 \mathrm{I}(85.42 \%)$ & 91 (81.25\%) & \\
\hline CHD, n (\%) & & & & & 0.022 \\
\hline No & 126 (63.32\%) & 18 (46.15\%) & 29 (60.42\%) & 79 (70.54\%) & \\
\hline Yes & 73 (36.68\%) & 21 (53.85\%) & 19 (39.58\%) & 33 (29.46\%) & \\
\hline CVD, n (\%) & & & & & 0.309 \\
\hline No & I 52 (76.38\%) & 32 (82.05\%) & 33 (68.75\%) & 87 (77.68\%) & \\
\hline Yes & 47 (23.62\%) & 7 (I7.95\%) & 15 (31.25\%) & 25 (22.32\%) & \\
\hline Sepsis, n (\%) & & & & & 0.386 \\
\hline No & I7| (85.93\%) & 32 (82.05\%) & 44 (91.67\%) & 95 (84.82\%) & \\
\hline Yes & 28 (14.07\%) & 7 (I7.95\%) & $4(8.33 \%)$ & 17 (15.18\%) & \\
\hline PVD, n (\%) & & & & & 0.646 \\
\hline No & 98 (49.25\%) & 19 (48.72\%) & 21 (43.75\%) & 58 (51.79\%) & \\
\hline Yes & IOI (50.75\%) & $20(51.28 \%)$ & 27 (56.25\%) & $54(48.21 \%)$ & \\
\hline
\end{tabular}

(Continued) 
Table I (Continued).

\begin{tabular}{|c|c|c|c|c|c|}
\hline Characteristics & All $(N=199)$ & $<60(\mathrm{~N}=39)$ & $60-89(N=48)$ & $\geq 90(N=\mid 12)$ & $P$ \\
\hline $\begin{array}{l}\text { Neuropathy, n (\%) } \\
\text { No } \\
\text { Yes }\end{array}$ & $\begin{array}{l}86(43.22 \%) \\
\text { II3 (56.78\%) }\end{array}$ & $\begin{array}{l}17(43.59 \%) \\
22(56.41 \%)\end{array}$ & $\begin{array}{l}18(37.50 \%) \\
30(62.50 \%)\end{array}$ & $\begin{array}{l}5 \mathrm{I}(45.54 \%) \\
6 \mathrm{I}(54.46 \%)\end{array}$ & 0.642 \\
\hline $\begin{array}{l}\text { Infection, n (\%) } \\
\text { Moderate } \\
\text { Severe }\end{array}$ & $\begin{array}{l}\text { II } 8 \text { (59.30\%) } \\
81 \text { (40.70\%) }\end{array}$ & $\begin{array}{l}20(51.28 \%) \\
19(48.72 \%)\end{array}$ & $\begin{array}{l}25(52.08 \%) \\
23(47.92 \%)\end{array}$ & $\begin{array}{l}73(65.18 \%) \\
39(34.82 \%)\end{array}$ & 0.159 \\
\hline \multicolumn{6}{|l|}{ Location } \\
\hline $\begin{array}{l}\text { Forefoot, n (\%) } \\
\text { No } \\
\text { Yes }\end{array}$ & $\begin{array}{l}19(9.55 \%) \\
180(90.45 \%)\end{array}$ & $\begin{array}{l}6(15.38 \%) \\
33(84.62 \%)\end{array}$ & $\begin{array}{l}5(10.42 \%) \\
43(89.58 \%)\end{array}$ & $\begin{array}{l}8(7.14 \%) \\
104(92.86 \%)\end{array}$ & 0.312 \\
\hline $\begin{array}{l}\text { Midfoot, n (\%) } \\
\text { No } \\
\text { Yes }\end{array}$ & $\begin{array}{l}184(92.46 \%) \\
\text { I5 (7.54\%) }\end{array}$ & $\begin{array}{l}33(84.62 \%) \\
6(15.38 \%)\end{array}$ & $\begin{array}{l}44(91.67 \%) \\
4(8.33 \%)\end{array}$ & $\begin{array}{l}107(95.54 \%) \\
5(4.46 \%)\end{array}$ & 0.082 \\
\hline $\begin{array}{l}\text { Hindfoot, n (\%) } \\
\text { No } \\
\text { Yes }\end{array}$ & $\begin{array}{l}183(91.96 \%) \\
16(8.04 \%)\end{array}$ & $\begin{array}{l}35(89.74 \%) \\
4(10.26 \%)\end{array}$ & $\begin{array}{l}45(93.75 \%) \\
3(6.25 \%)\end{array}$ & $\begin{array}{l}103(91.96 \%) \\
9(8.04 \%)\end{array}$ & 0.792 \\
\hline $\begin{array}{l}\text { All-cause mortality n (\%) } \\
\text { Survival } \\
\text { Dead }\end{array}$ & $\begin{array}{l}\mid 48 \text { (74.37\%) } \\
5 \mid(25.63 \%)\end{array}$ & $\begin{array}{l}24(61.54 \%) \\
15(38.46 \%)\end{array}$ & $\begin{array}{l}30(62.50 \%) \\
18(37.50 \%)\end{array}$ & $\begin{array}{l}94 \text { (83.93\%) } \\
18 \text { (16.07\%) }\end{array}$ & 0.002 \\
\hline $\begin{array}{l}\text { MACE, n (\%) } \\
\text { No } \\
\text { Yes }\end{array}$ & $\begin{array}{l}\text { I34(71.28\%) } \\
54(28.72 \%)\end{array}$ & $\begin{array}{l}19(54.29 \%) \\
16(45.71 \%)\end{array}$ & $\begin{array}{l}28(60.87 \%) \\
18(39.13 \%)\end{array}$ & $\begin{array}{l}87(81.31 \%) \\
20(18.69 \%)\end{array}$ & 0.002 \\
\hline
\end{tabular}

Notes: Mean \pm standard deviation (SD) and Median (Inter Quartile Range) for continuous variables. Percentage (\%) for categorical variables.

Abbreviations: SCr, serum creatinine; eGFR, estimated glomerular filtration rate; UACR, urinary albumin-to-creatinine ratio; HbAIc, glycosylated hemoglobin; WBC, white blood cells; Hb, hemoglobin; TC, total cholesterol; TG, triglycerides; HDL-C, high-density lipoprotein cholesterol; LDL-C, low-density lipoprotein cholesterol; apoAI, apolipoprotein AI; apoB, apolipoprotein B; ABI, ankle brachial index; T2DM, type 2 diabetes mellitus; CHD, coronary heart disease; CVD, cardiovascular diseases; PVD, peripheral arterial diseases; MACE, major cardiovascular adverse events.

associated with 3-year all-cause mortality and MACE (Tables 2 and 3). Then, we established three models in order to explore the associations between eGFR levels and all-cause mortality or MACE (Table 4). In the crude model, compared patients with abnormal kidney function, patients with normal kidney function exhibited lower incidence of all-cause mortality (HR $0.36 ; 95 \%$ CI: $0.20-0.64 ; P<0.01$ ) and MACE (HR $0.37 ; 95 \% \mathrm{CI}$ : $0.22-0.65 ; P<0.01$ ). Model I (adjustment for age, sex, smoke and duration of diabetes) and Model II (adjustment for Model I, SCR, CHD, hindfoot, infection, sepsis and $\mathrm{ABI}$ ) also showed that patients with normal kidney function had lower incidence of all-cause mortality with HRs of 0.42 (95\% CI: $0.24-0.75 ; P<0.01)$ and 0.43 (95\% CI: $0.22-0.85 ; P<0.01)$, respectively and MACE with HRs of 0.43 (95\% CI: $0.33-0.75 ; P<0.01)$ and 0.51 (95\% CI: $0.27-0.96 ; P<0.05$ ), respectively.

\section{Stratified Analysis by Sex}

To explore the influence of sex on the association of eGFR with the clinical outcomes, Table 5 shows the stratified analysis by sex for HRs of all-cause mortality and MACE by eGFR. Our results suggested that in both the unadjusted and adjusted models, compared to eGFR $<90 \mathrm{~mL} / \mathrm{min} /$ $1.73 \mathrm{~m}^{2}$, eGFR $\geq 90 \mathrm{~mL} / \mathrm{min} / 1.73 \mathrm{~m}^{2}$ was independently associated with decreased risk of all-cause mortality (crude model: HR $0.29,95 \%$ CI $0.14-0.60, P<0.01$; Model I: HR 0.29; 95\% CI 0.14-0.61, $P<0.01$; Model II: HR $0.33 ; 95 \%$ CI $0.14-0.76, P<0.01)$ and MACE (crude model: HR $0.28,95 \%$ CI $0.13-0.60, P<0.01$; Model I: HR 0.25 ; 95\% CI $0.12-0.56, P<0.01$; Model II: HR $0.27 ; 95 \%$ CI $0.11-0.65, P<0.01$ ) in male, but not in female (crude model: HR $0.56,95 \%$ CI $0.22-1.55, P>$ 0.05; Model I: HR 0.72; 95\% CI 0.26-2.02, $P>0.05$; Model II: HR 0.35 ; $95 \%$ CI $0.09-1.40, P>0.05$ ) and 

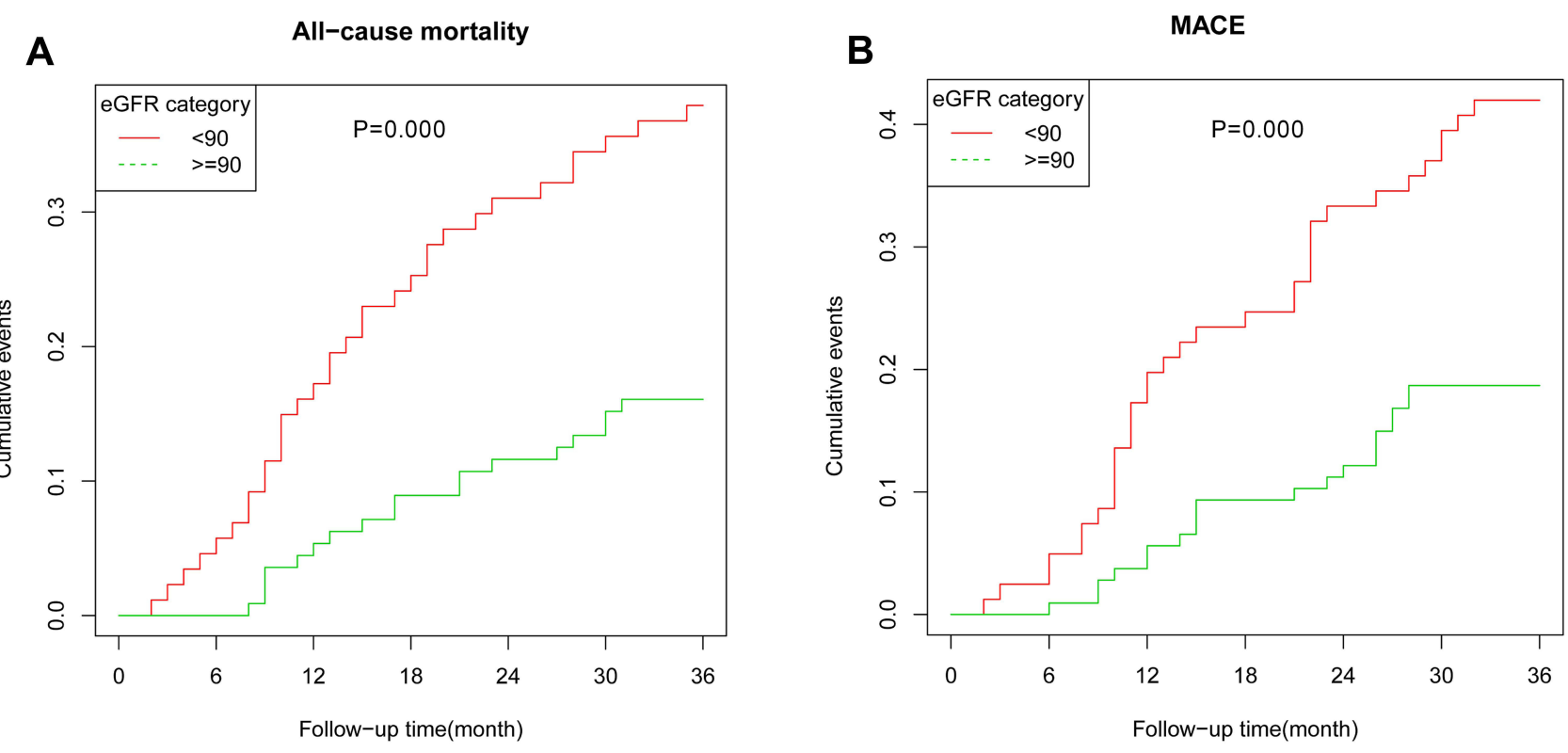

Figure I Kaplan-Meier curves of the cumulative incidence of all-cause mortality (A) and MACE (B) stratified by eGFR groups.

MACE (crude model: HR 0.57, 95\% CI $0.24-1.33, P>$ 0.05; Model I: HR 0.78; 95\% CI 0.32-1.93, $P>0.05$; Model II: HR 1.27; 95\% CI 0.33-4.87, $P>0.05$ ), which implied that the association of eGFR with the clinical outcomes may be confounded by sex.

\section{Discussion}

In this study, among the patients, 39 individuals had moderately to severely decreased kidney function, 48 individuals had mildly decreased kidney function and 112 individuals had normal kidney function. At study initiation, patients with higher eGFR had lower $\mathrm{SCr}$ and lower UACR and were more likely to have a history of CHD. During a 3-year follow-up, all-cause mortality occurred in 51 patients among 199 participants, 54 had MACE in 188 participants and 26 of them died. After fully adjusting for potential confounders, compared to eGFR $<90 \mathrm{~mL} / \mathrm{min} /$ $1.73 \mathrm{~m}^{2}$, eGFR $\geq 90 \mathrm{~mL} / \mathrm{min} / 1.73 \mathrm{~m}^{2}$ had lower incidence of all-cause mortality and MACE. Additionally, when compared to eGFR $<90 \mathrm{~mL} / \mathrm{min} / 1.73 \mathrm{~m}^{2}$, eGFR $\geq$ $90 \mathrm{~mL} / \mathrm{min} / 1.73 \mathrm{~m}^{2}$ was independently associated with decreased risk of all-cause mortality and MACE in male, but not in female.

In our study, $43.72 \%$ of the patients with DFO showed eGFR $<90 \mathrm{~mL} / \mathrm{min} / 1.73 \mathrm{~m}^{2}$. Of these, $19.60 \%$ was eGFR $<60 \mathrm{~mL} / \mathrm{min} / 1.73 \mathrm{~m}^{2}$ and $24.12 \%$ was eGFR 60 to $89 \mathrm{~mL} /$ $\min / 1.73 \mathrm{~m}^{2}$. It is not only higher than the proportion of diabetic patients with chronic kidney disease $(20-40 \%),{ }^{20}$ but also higher than the proportion of patients with diabetic foot disease complicated with chronic kidney disease $(39.3 \%) .^{21}$ There were significant differences in the prevalence of CHD among the three groups, which suggests that DFO with poorer kidney function was more likely to have CHD. CHD is one of the main causes of death in patients with diabetic foot disease. ${ }^{22}$ There is evidence that the survival rate of CHD patients with renal insufficiency is lower, ${ }^{23}$ which is closely related to renal insufficiency. ${ }^{24,25}$ Inflammation and atherosclerosis are involved in the common pathogenesis of chronic kidney disease and CHD, so they may be the underlying causes of the above findings. ${ }^{26,27}$ There was no significant difference in HbAlc between the three groups. However, glucose metabolism and insulin action in diabetic patients are profoundly altered by a decrease in eGFR. Glycemic assessment by $\mathrm{HbAlc}$ is hampered by a variety of CKDassociated conditions, which makes the measured value either low or high. Alternative glycemic biomarkers, such as glycated albumin or fructosamine, are not fully validated. ${ }^{28}$ Therefore, whether salivary amylase and salivary glucose concentration, relatively novel blood glucose indicators, ${ }^{29}$ can effectively reflect the actual blood glucose level of CKD is worthy of further study. There was no significant difference between the three groups regarding the location of the diabetic foot wound. The location of the diabetic foot wound should be related to the Foot Posture Index. ${ }^{30}$ 
Table 2 Univariate Cox Proportional Hazard Model of eGFR Levels for All-Cause Mortality $(n=199)$

\begin{tabular}{|c|c|c|c|}
\hline Characteristics & HR & $95 \% \mathrm{Cl}$ & $-P$-value \\
\hline \multicolumn{4}{|l|}{ Sex } \\
\hline Female & 1.00 & - & - \\
\hline Male & 1.36 & $(0.75-2.46)$ & 0.3090 \\
\hline Age & 1.05 & $(1.03-1.07)$ & $<0.0001$ \\
\hline BMI & 0.95 & $(0.88-1.02)$ & 0.1253 \\
\hline Duration of diabetes & 0.97 & $(0.93-1.02)$ & 0.2483 \\
\hline \multicolumn{4}{|l|}{ Smoke } \\
\hline No & 1.00 & - & - \\
\hline Yes & 1.25 & $(0.7 I-2.18)$ & 0.4393 \\
\hline \multicolumn{4}{|l|}{ Hypertension } \\
\hline No & 1.00 & - & - \\
\hline Yes & 1.29 & $(0.6 \mathrm{I}-2.75)$ & 0.5049 \\
\hline \multicolumn{4}{|l|}{ CHD } \\
\hline No & 1.00 & - & - \\
\hline Yes & 2.07 & $(1.20-3.59)$ & 0.0095 \\
\hline \multicolumn{4}{|l|}{ CVD } \\
\hline No & 1.00 & - & - \\
\hline Yes & 1.31 & $(0.72-2.39)$ & 0.3838 \\
\hline \multicolumn{4}{|l|}{ Sepsis } \\
\hline No & 1.00 & - & - \\
\hline Yes & 2.49 & $(1.32-4.67)$ & 0.0046 \\
\hline \multicolumn{4}{|l|}{ Infection } \\
\hline Moderate & 1.00 & - & - \\
\hline Severe & 3.26 & $(1.83-5.79)$ & $<0.000 \mathrm{I}$ \\
\hline \multicolumn{4}{|l|}{ Neuropathy } \\
\hline No & 1.00 & - & - \\
\hline Yes & 1.61 & $(0.90-2.88)$ & 0.1091 \\
\hline \multicolumn{4}{|l|}{ TEXAS } \\
\hline $3 B$ & 1.00 & - & - \\
\hline $3 \mathrm{D}$ & 1.16 & $(0.67-2.02)$ & 0.5964 \\
\hline \multicolumn{4}{|l|}{ Forefoot } \\
\hline No & 1.00 & - & - \\
\hline Yes & 1.33 & $(0.48-3.69)$ & 0.5831 \\
\hline \multicolumn{4}{|l|}{ Midfoot } \\
\hline No & 1.00 & - & - \\
\hline Yes & 1.69 & $(0.72-3.97)$ & 0.2268 \\
\hline \multicolumn{4}{|l|}{ Hindfoot } \\
\hline No & 1.00 & - & - \\
\hline Yes & 4.92 & $(2.56-9.48)$ & $<0.0001$ \\
\hline $\mathrm{HbAlc}$ & 0.95 & $(0.83-1.08)$ & 0.45570 \\
\hline WBC & 1.02 & $(0.92-1.12)$ & 0.7133 \\
\hline $\mathrm{Hb}$ & 1.01 & $(0.99-1.02)$ & 0.3347 \\
\hline
\end{tabular}

(Continued)
Table 2 (Continued).

\begin{tabular}{|l|c|c|c|}
\hline Characteristics & HR & $\mathbf{9 5 \%} \mathbf{C l}$ & -P-value \\
\hline TC & 1.08 & $(0.92-1.27)$ & 0.3317 \\
TG & 1.34 & $(0.83-2.18)$ & 0.2310 \\
HDL & 0.59 & $(0.28-1.21)$ & 0.1505 \\
LDL & 1.05 & $(0.78-1.4 I)$ & 0.7378 \\
apoAI & 1.07 & $(0.38-2.99)$ & 0.8941 \\
apoB & 1.02 & $(0.34-3.11)$ & 0.9678 \\
SCr & 1.01 & $(I .00-1.01)$ & 0.0037 \\
ABI & 0.36 & $(0.16-0.8 I)$ & 0.0133 \\
\hline
\end{tabular}

Abbreviations: $\mathrm{HR}$, hazard ratio; $\mathrm{Cl}$, confidence interval; $\mathrm{BMI}$, body mass index; CHD, coronary heart disease; CVD, cardiovascular diseases; MACE, major cardiovascular adverse events; HbAlc, glycosylated hemoglobin; WBC, white blood cells; $\mathrm{Hb}$, hemoglobin; TC, total cholesterol; TG, triglycerides; HDL-C, high-density lipoprotein cholesterol; LDL-C, low-density lipoprotein cholesterol; apoAI, apolipoprotein $\mathrm{Al}$; apoB, apolipoprotein $\mathrm{B} ; \mathrm{SCr}$, serum creatinine; $\mathrm{ABI}$, ankle brachial index.

At present, there are still few studies on MACE of diabetic foot disease. In this study, 54 cases $(28.72 \%)$ had MACE, 26 of them died, and the mortality rate of MACE was $48.15 \%$. A recent study by Hung et $\mathrm{al}^{31}$ showed that the incidence of MACE in patients with diabetic foot disease during hospitalization was $1.86 \%$ and the mortality rate of MACE patients was $47.62 \%$. Their results were similar to ours, but the incidence of MACE in their study is different from our study. There are two reasons for consideration: one is that our observation is 3-year cumulative occurrence of MACE, while Hung's observation time was only $30.0 \pm 25.0$ days, and they only observed what happened during the patient's hospitalization; secondly, they assessed diabetic foot disease using Wagner grade 1-5 ulcers; however, we assessed DFO using Wagner grade 3 and above only. ${ }^{32}$ Hence, our patients had more complicated conditions and more severe infections. The survival analysis showed that there was a significant difference in the cumulative risk of MACE between the decreased eGFR group and the normal eGFR group, and the decreased eGFR group had a higher risk of MACE as the observation time extended. He et $\mathrm{al}^{21}$ followed up with patients for 3 years and explored the association between eGFR and cardiovascular events. They showed about $50 \%$ of patients with diabetic foot ulcers (DFU) in the decreased eGFR group had cardiovascular events, but less than $30 \%$ of the DFU patients in the normal eGFR group had cardiovascular events, which is similar to the results in our study. Previous studies ${ }^{33}$ have shown that moderately and severely decreased kidney function (eGFR $\leq 60 \mathrm{~mL} / \mathrm{min} / 1.73 \mathrm{~m}^{2}$ ) is an independent predictor of cardiovascular events in diabetic patients. Our 
Table 3 Univariate Cox Proportional Hazard Model of eGFR Levels for MACE $(n=188)$

\begin{tabular}{|c|c|c|c|}
\hline Characteristics & HR & $95 \% \mathrm{Cl}$ & $P$-value \\
\hline \multicolumn{4}{|l|}{ Sex } \\
\hline Female & 1.00 & - & - \\
\hline Male & 0.98 & $(0.57-1.70)$ & 0.9477 \\
\hline Age & 1.05 & $(1.03-1.08)$ & $<0.0001$ \\
\hline BMI & 0.95 & $(0.89-1.02)$ & 0.1674 \\
\hline Duration of diabetes & 0.98 & $(0.94-1.03)$ & 0.5070 \\
\hline \multicolumn{4}{|l|}{ Smoke } \\
\hline No & 1.00 & - & - \\
\hline Yes & 1.74 & $(0.99-3.07)$ & 0.0539 \\
\hline \multicolumn{4}{|l|}{ Hypertension } \\
\hline No & 1.00 & - & - \\
\hline Yes & 1.48 & $(0.70-3.14)$ & 0.3059 \\
\hline \multicolumn{4}{|l|}{ CHD } \\
\hline No & 1.00 & - & - \\
\hline Yes & 3.3 & $(1.90-5.74)$ & $<0.0001$ \\
\hline \multicolumn{4}{|l|}{ CVD } \\
\hline No & 1.00 & - & - \\
\hline Yes & 1.31 & $(0.73-2.35)$ & 0.3665 \\
\hline \multicolumn{4}{|l|}{ Sepsis } \\
\hline No & 1.00 & - & - \\
\hline Yes & 0.7 & $(0.25-1.95)$ & 0.5006 \\
\hline \multicolumn{4}{|l|}{ Infection } \\
\hline Moderate & 1.00 & - & - \\
\hline Severe & 2.52 & $(1.47-4.31)$ & 0.0008 \\
\hline \multicolumn{4}{|l|}{ Neuropathy } \\
\hline No & 1.00 & - & - \\
\hline Yes & 1.24 & $(0.7 I-2.14)$ & 0.4489 \\
\hline \multicolumn{4}{|l|}{ TEXAS } \\
\hline $3 B$ & 1.00 & - & - \\
\hline $3 D$ & 0.97 & $(0.57-1.65)$ & 0.9015 \\
\hline \multicolumn{4}{|l|}{ Forefoot } \\
\hline No & 1.00 & - & - \\
\hline Yes & 1.5 & $(0.54-4.15)$ & 0.4349 \\
\hline \multicolumn{4}{|l|}{ Midfoot } \\
\hline No & 1.00 & - & - \\
\hline Yes & 1.51 & $(0.64-3.52)$ & 0.3435 \\
\hline \multicolumn{4}{|l|}{ Hindfoot } \\
\hline No & 1.00 & - & - \\
\hline Yes & 4.48 & $(2.34-8.57)$ & $<0.0001$ \\
\hline HbAlc & 0.97 & $(0.86-1.10)$ & $0.634 I$ \\
\hline WBC & 1.06 & $(0.96-1.16)$ & 0.2595 \\
\hline $\mathrm{Hb}$ & 0.99 & $(0.98-1.01)$ & 0.3766 \\
\hline
\end{tabular}

(Continued)
Table 3 (Continued).

\begin{tabular}{|l|c|c|c|}
\hline Characteristics & HR & 95\% Cl & $P$-value \\
\hline TC & 1.12 & $(0.96-1.30)$ & 0.1669 \\
TG & 1.15 & $(0.72-1.82)$ & 0.5683 \\
HDL & 0.73 & $(0.36-1.47)$ & 0.3720 \\
LDL & 1.02 & $(0.76-1.35)$ & 0.9176 \\
apoAI & 1.17 & $(0.43-3.18)$ & 0.7529 \\
apoB & 1.41 & $(0.48-4.15)$ & 0.5334 \\
SCR & 1.01 & $(1.00-1.01)$ & 0.0046 \\
ABI & 0.38 & $(0.17-0.84)$ & 0.0162 \\
\hline
\end{tabular}

Abbreviations: MACE, major cardiovascular adverse events; $\mathrm{HR}$, hazard ratio; $\mathrm{Cl}$, confidence interval; BMI, body mass index; CHD, coronary heart disease; CVD, cardiovascular diseases; MACE, major cardiovascular adverse events; HbAlc, glycosylated hemoglobin; WBC, white blood cells; Hb, hemoglobin; TC, total cholesterol; TG, triglycerides; HDL-C, high-density lipoprotein cholesterol; LDL-C, lowdensity lipoprotein cholesterol; apoAI, apolipoprotein AI; apoB, apolipoprotein B; $S C r$, serum creatinine; $A B I$, ankle brachial index.

Table 4 Multivariate Cox Proportional Hazard Model of Association of eGFR Levels with All-Cause Mortality and MACE

\begin{tabular}{|l|l|l|c|c|}
\hline $\begin{array}{l}\text { Clinical } \\
\text { Outcome }\end{array}$ & eGFR Category & HR & $95 \%$ CI & P-value \\
\hline \multicolumn{4}{|l|}{ All-cause mortality } & \multicolumn{3}{|l|}{} \\
\hline Crude model & eGFR $<90$ & 1.00 & - & - \\
& eGFR $\geq 90$ & 0.36 & $(0.20-0.64)$ & 0.001 \\
\hline Model I & eGFR $<90$ & 1.00 & - & - \\
& eGFR $\geq 90$ & 0.42 & $(0.24-0.75)$ & 0.004 \\
\hline Model II & eGFR $<90$ & 1.00 & - & - \\
& eGFR $\geq 90$ & 0.43 & $(0.22-0.85)$ & 0.015 \\
\hline MACE & \multicolumn{4}{|l|}{} \\
\hline Crude model & eGFR $<90$ & 1.00 & - & - \\
& eGFR $\geq 90$ & 0.37 & $(0.22-0.65)$ & 0.001 \\
\hline Model I & eGFR $<90$ & 1.00 & - & - \\
& eGFR $\geq 90$ & 0.43 & $(0.33-0.75)$ & 0.003 \\
\hline Model II & eGFR $<90$ & 1.00 & - & - \\
& eGFR $\geq 90$ & 0.51 & $(0.27-0.96)$ & 0.038 \\
\hline
\end{tabular}

Notes: Crude model adjust for none. Model I: adjust for age, sex, smoke, duration of diabetes. Model II: adjust for age, sex, smoke, duration of diabetes, SCR, CHD, hindfoot, infection, sepsis and ABI. Models for all-cause mortality $(n=199)$; models for MACE $(n=188)$.

Abbreviations: $\mathrm{HR}$, hazard ratio; $\mathrm{Cl}$, confidence interval.

study further suggested that decreased GFR is a risk factor for MACE in patients with DFO compared with the normal eGFR. We also found that there was a significant difference in the cumulative risk rate of all-cause mortality between the decreased eGFR group and the normal eGFR group. With the extension of the observation time, patients in the decreased eGFR group had a higher risk of all-cause 
Table 5 Stratified Analysis by Sex of eGFR Levels with All-Cause Mortality and MACE by Sex

\begin{tabular}{|c|c|c|c|c|c|}
\hline Sex & $\begin{array}{l}\text { Clinical } \\
\text { Outcome }\end{array}$ & eGFR Category & HR & $95 \% \mathrm{Cl}$ & $P$-value \\
\hline \multirow[t]{14}{*}{ Female } & $\begin{array}{l}\text { All-cause } \\
\text { mortality }\end{array}$ & & & & \\
\hline & \multirow[t]{2}{*}{ Crude model } & eGFR $<90$ & 1.00 & - & - \\
\hline & & eGFR $\geq 90$ & 0.56 & $(0.22-1.55)$ & 0.276 \\
\hline & \multirow[t]{2}{*}{ Model I } & eGFR $<90$ & 1.00 & - & - \\
\hline & & eGFR $\geq 90$ & 0.72 & $(0.26-2.02)$ & 0.532 \\
\hline & \multirow[t]{2}{*}{ Model II } & eGFR $<90$ & 1.00 & - & - \\
\hline & & eGFR $\geq 90$ & 0.35 & $(0.09-1.40)$ & 0.136 \\
\hline & \multicolumn{5}{|l|}{ MACE } \\
\hline & \multirow[t]{2}{*}{ Crude model } & eGFR $<90$ & 1.00 & - & - \\
\hline & & eGFR $\geq 90$ & 0.57 & $(0.24-1.33)$ & 0.192 \\
\hline & \multirow[t]{2}{*}{ Model I } & eGFR $<90$ & 1.00 & - & - \\
\hline & & eGFR $\geq 90$ & 0.78 & $(0.32-1.93)$ & 0.59 \\
\hline & \multirow[t]{2}{*}{ Model II } & eGFR $<90$ & 1.00 & - & - \\
\hline & & eGFR $\geq 90$ & 1.27 & $(0.33-4.87)$ & 0.727 \\
\hline \multirow[t]{14}{*}{ Male } & $\begin{array}{l}\text { All-cause } \\
\text { mortality }\end{array}$ & & & & \\
\hline & \multirow[t]{2}{*}{ Crude model } & eGFR $<90$ & 1.00 & - & - \\
\hline & & eGFR $\geq 90$ & 0.29 & $(0.14-0.60)$ & 0.001 \\
\hline & \multirow[t]{2}{*}{ Model I } & eGFR $<90$ & 1.00 & - & - \\
\hline & & eGFR $\geq 90$ & 0.29 & $(0.14-0.61)$ & 0.001 \\
\hline & \multirow[t]{2}{*}{ Model II } & eGFR $<90$ & 1.00 & - & - \\
\hline & & eGFR $\geq 90$ & 0.33 & $(0.14-0.76)$ & 0.010 \\
\hline & \multicolumn{5}{|l|}{ MACE } \\
\hline & \multirow[t]{2}{*}{ Crude model } & eGFR $<90$ & 1.00 & - & - \\
\hline & & eGFR $\geq 90$ & 0.28 & $(0.13-0.60)$ & 0.001 \\
\hline & \multirow[t]{2}{*}{ Model I } & eGFR $<90$ & 1.00 & - & - \\
\hline & & eGFR $\geq 90$ & 0.25 & $(0.12-0.56)$ & 0.001 \\
\hline & \multirow[t]{2}{*}{ Model II } & eGFR $<90$ & 1.00 & - & - \\
\hline & & eGFR $\geq 90$ & 0.27 & $(0.11-0.65)$ & 0.004 \\
\hline
\end{tabular}

Notes: Crude model adjust for none. Model I: adjust for age, smoke, duration of diabetes. Model II: adjust for age, smoke, duration, SCR, CHD, hindfoot, infection, sepsis and ABI. Models for all-cause mortality $(n=199)$; models for MACE $(n=188)$. Abbreviations: $\mathrm{HR}$, hazard ratio; $\mathrm{Cl}$, confidence interval.

mortality, suggesting that renal insufficiency increases the risk of all-cause mortality in DFO patients. Previous studies $^{22,34}$ suggested that decreased eGFR was a risk factor for death in patients with diabetic foot disease, which was further confirmed in this study.

However, few studies estimated this association between male and female. In the present work, we found that in male with DFO, the decreased eGFR is closely associated with all-cause mortality and MACE only, but the results were absent in female. Male sex is a known risk factor associated with the incidence of cardiovascular events. Previous related research studies support this result. Orozco-Beltrán et $\mathrm{al}^{35}$ found that in older diabetic patients, male had a higher risk of MACE than female. Pilote et $\mathrm{al}^{36}$ also reported that females have a lower mortality rate of cardiovascular disease (CVD) than male. The possible reason may be due to cardiovascular protective effects of estrogen. Estrogen has the endothelium-dependent vasodilation, anti-inflammatory effects and antioxidant properties that can enhance vasodilation, improve lipid metabolism, atherosclerosis and CVD. ${ }^{37}$ Besides, estrogen also exerts protective effects on the kidney. Clinical studies $^{38}$ reported that female have a lower incidence of chronic renal disease than male across the lifespan. Animal study ${ }^{39}$ found that male mice are more commonly affected than female mice in the mouse models of renal injury, and estrogen therapy can effectively increase tolerance to ischemia-reperfusion injury. The mechanism may be because estrogen has proliferative and antiapoptotic effects on proximal tubular cells. In our study, female were mostly middle-aged to elderly and were in menopause status, but estrogen exerts the long-term protective effect on cardiovascular systems and kidney in premenopausal women, so the relevant studies all confirmed that our data and conclusions are credible.

There are still some shortcomings in this research. First, the patients who were not followed up and lost to follow-up were excluded. The outcomes of these patients are unknown, and the true mortality rate may be underestimated. Second, patients with malignant tumors were not excluded when the patients were enrolled, and the cause of death of some patients may be related to malignant tumors. Third, more basic trials are needed to clarify the mechanism behind the relationship between eGFR levels and the clinical outcomes of patients with DFO; further, clinical trials are needed to determine whether the treatment of renal dysfunction is beneficial to improve the clinical outcomes of patients with DFO.

\section{Conclusions}

In summary, decreased eGFR is a risk factor for all-cause mortality and MACE in individuals with DFO. Additionally, male with decreased eGFR had a higher risk of all-cause mortality and MACE, but female did not. 


\section{Ethics Approval and Consent to Participate}

Written informed consent were provided by all participants prior to undergoing any study-related procedures. This study was conducted in accordance with the Declaration of Helsinki and approved by the Ethics Committee of Guangxi Academy of Medical Sciences and the People's Hospital of Guangxi Zhuang Autonomous Region.

\section{Acknowledgments}

Thanks to nurses Li Zhang and Xiulu Huang for providing some patient information from the Podiatry Studio of the Department of Endocrinology and Metabolism, People's Hospital of Guangxi Zhuang Autonomous Region. Thank you Guangxi Academy of Medical Sciences and the People's Hospital of Guangxi Zhuang Autonomous Region Information Network Center and Medical Record Information Quality Control Department for assisting in retrieving medical records.

\section{Author Contributions}

All authors made a significant contribution to the work reported, whether that is in the conception, study design, execution, acquisition of data, analysis and interpretation, or in all these areas; took part in drafting, revising or critically reviewing the article; gave final approval of the version to be published; have agreed on the journal to which the article has been submitted; and agree to be accountable for all aspects of the work.

\section{Funding}

This research was funded by the Natural Science Foundation of China (81560044, 30860113), Guangxi Medical and Health Appropriate Technology Research and Development Project (S201422-01), Shanxi Health Research Project (2019165) and Guangxi Zhuang Autonomous Region Health Committee Project (Z20190209).

\section{Disclosure}

The authors declare that they have no competing interests.

\section{References}

1. Senneville EM, Lipsky BA, van Asten SAV, Peters EJ. Diagnosing diabetic foot osteomyelitis. Diabetes Metab Res Rev. 2020;36(Suppl 1):e3250. doi:10.1002/dmrr.3250

2. Li Y, Teng D, Shi X, et al. Prevalence of diabetes recorded in mainland China using 2018 diagnostic criteria from the American Diabetes Association: national cross sectional study. BMJ. 2020;369:m997. doi:10.1136/bmj.m997
3. Navarro-Flores E, Gijon-Nogueron G, Cervera-Marin JA, LabajosManzanares MT. Assessment of foot self-care in patients with diabetes: retrospective Assessment (2008-2014). Foot Ankle Spec. 2015;8(5):406-412. doi:10.1177/1938640015585963

4. Navarro-Flores E, Perez-Ros P, Martinez-Arnau FM, Julian-Rochina I, Cauli O. Neuro-psychiatric alterations in patients with diabetic foot syndrome. CNS Neurol Disord Drug Targets. 2019;18(8):598-608. doi:10.2174/1871527318666191002094406

5. Jiang Y, Wang X, Xia L, et al. A cohort study of diabetic patients and diabetic foot ulceration patients in China. Wound Repair Regen. 2015;23(2):222-230. doi:10.1111/wrr.12263

6. Walsh JW, Hoffstad OJ, Sullivan MO, Margolis DJ. Association of diabetic foot ulcer and death in a population-based cohort from the United Kingdom. Diabet Med. 2016;33(11):1493-1498. doi:10.1111/dme.13054

7. Zeun P, Gooday C, Nunney I, Dhatariya K. Predictors of outcomes in diabetic foot osteomyelitis treated initially with conservative (nonsurgical) medical management: a retrospective study. Int $J$ Low Extrem Wounds. 2016;15(1):19-25. doi:10.1177/1534734615596892

8. Schaper NC, van Netten JJ, Apelqvist J, et al. Practical guidelines on the prevention and management of diabetic foot disease (IWGDF 2019 update). Diabetes Metab Res Rev. 2020;36(Suppl 1):e3266. doi: $10.1002 / \mathrm{dmrr} .3266$

9. Navarro-Flores E, Cauli O. Quality of life in individuals with diabetic foot syndrome. Endocr Metab Immune Disord Drug Targets. 2020;20 (9):1365-1372. doi:10.2174/1871530320666200128154036

10. Megallaa MH, Ismail AA, Zeitoun MH, Khalifa MS. Association of diabetic foot ulcers with chronic vascular diabetic complications in patients with type 2 diabetes. Diabetes Metab Syndr. 2019;13 (2):1287-1292. doi:10.1016/j.dsx.2019.01.048

11. Buyadaa O, Magliano DJ, Salim A, Koye DN, Shaw JE. Risk of rapid kidney function decline, all-cause mortality, and major cardiovascular events in nonalbuminuric chronic kidney disease in type 2 diabetes. Diabetes Care. 2020;43(1):122-129. doi:10.2337/dc19-1438

12. Allison GM, Flanagin E. How ESKD complicates the management of diabetic foot ulcers: the vital role of the dialysis team in prevention, early detection, and support of multidisciplinary treatment to reduce lower extremity amputations. Semin Dial. 2020;33(3):245-253. doi:10.1111/sdi.12875

13. Alberti KG, Zimmet PZ. Definition, diagnosis and classification of diabetes mellitus and its complications. Part 1: diagnosis and classification of diabetes mellitus provisional report of a WHO consultation. Diabet Med. 1998;15(7):539-553. doi:10.1002/(SICI) 1096-9136(199807)15:7<539::AID-DIA668>3.0.CO;2-S

14. Lipsky BA, Senneville E, Abbas ZG, et al. Guidelines on the diagnosis and treatment of foot infection in persons with diabetes (IWGDF 2019 update). Diabetes Metab Res Rev. 2020;36(Suppl 1): e3280. doi:10.1002/dmrr.3280

15. Ontario H. Skin substitutes for adults with diabetic foot ulcers and venous leg ulcers: a health technology assessment. Ont Health Technol Assess Ser. 2021;21(7):1-165.

16. Stevens PE, Levin A; Kidney Disease: Improving Global Outcomes Chronic Kidney Disease Guideline Development Work Group M. Evaluation and management of chronic kidney disease: synopsis of the kidney disease: improving global outcomes 2012 clinical practice guideline. Ann Intern Med. 2013;158(11):825-830. doi:10.7326/ 0003-4819-158-11-201306040-00007

17. Ma YC, Zuo L, Chen JH, et al. Modified glomerular filtration rate estimating equation for Chinese patients with chronic kidney disease. $J$ Am Soc Nephrol. 2006;17(10):2937-2944. doi:10.1681/ ASN.2006040368

18. Monteiro-Soares M, Russell D, Boyko EJ, et al. Guidelines on the classification of diabetic foot ulcers (IWGDF 2019). Diabetes Metab Res Rev. 2020;36(Suppl 1):e3273. doi:10.1002/dmrr.3273

19. Lavery LA, Armstrong DG, Harkless LB. Classification of diabetic foot wounds. J Foot Ankle Surg. 1996;35(6):528-531. doi:10.1016/ s1067-2516(96)80125-6 
20. American Diabetes Association. 11. microvascular complications and foot care: standards of medical care in diabetes-2021. Diabetes Care. 2021;44(Suppl1):S151-S167. doi:10.2337/dc21-S011.

21. He Y, Qian H, Xu L, et al. Association between estimated glomerular filtration rate and outcomes in patients with diabetic foot ulcers: a 3-year follow-up study. Eur J Endocrinol. 2017;177(1):41-50. doi:10.1530/EJE-17-0070

22. Morbach S, Furchert H, Groblinghoff U, et al. Long-term prognosis of diabetic foot patients and their limbs: amputation and death over the course of a decade. Diabetes Care. 2012;35(10):2021-2027. doi: $10.2337 / \mathrm{dc} 12-0200$

23. Saran R, Robinson B, Abbott KC, et al. US renal data system 2019 annual data report: epidemiology of kidney disease in the United States. Am J Kidney Dis. 2020;75(1Suppl 1):A6-A7. doi:10.1053/j. ajkd.2019.09.003

24. Anavekar NS, McMurray JJ, Velazquez EJ, et al. Relation between renal dysfunction and cardiovascular outcomes after myocardial infarction. $N$ Engl J Med. 2004;351(13):1285-1295. doi:10.1056/ NEJMoa041365

25. Chertow GM, Normand SL, Silva LR, McNeil BJ. Survival after acute myocardial infarction in patients with end-stage renal disease: results from the cooperative cardiovascular project. Am J Kidney Dis. 2000;35(6):1044-1051. doi:10.1016/s0272-6386(00)70038-2

26. Chen TK, Knicely DH, Grams ME. Chronic kidney disease diagnosis and management: a review. JAMA. 2019;322(13):1294-1304. doi:10.1001/jama.2019.14745

27. Herzog CA, Asinger RW, Berger AK, et al. Cardiovascular disease in chronic kidney disease. A clinical update from Kidney Disease: Improving Global Outcomes (KDIGO). Kidney Int. 2011;80 (6):572-586. doi:10.1038/ki.2011.223

28. Galindo RJ, Beck RW, Scioscia MF, Umpierrez GE, Tuttle KR. Glycemic monitoring and management in advanced chronic kidney disease. Endocr Rev. 2020;41(5):756-774. doi:10.1210/endrev/ bnaa017

29. Perez-Ros P, Navarro-Flores E, Julian-Rochina I, Martinez-Arnau FM, Cauli O. Changes in salivary amylase and glucose in diabetes: a scoping review. Diagnostics (Basel). 2021;11(3):453. doi:10.3390/ diagnostics 11030453
30. Simon-Perez E, Simon-Perez C, Alonso-Pena D, et al. Stiffness degree of ankle range of motion in diabetic patients with atypical amputation. Rev Assoc Med Bras (1992). 2020;66(2):216-221. doi:10.1590/1806-9282.66.2.216

31. Hung SY, Huang YY, Hsu LA, et al. Treatment for diabetic foot ulcers complicated by major cardiac events. Can J Diabetes. 2015;39 (3):183-187. doi:10.1016/j.jcjd.2014.11.002

32. Wagner FW. The dysvascular foot: a system for diagnosis and treatment. Foot Ankle. 1981;2(2):64-122. doi:10.1177/ 107110078100200202

33. Ninomiya T, Perkovic V, de Galan BE, et al. Albuminuria and kidney function independently predict cardiovascular and renal outcomes in diabetes. J Am Soc Nephrol. 2009;20(8):1813-1821. doi:10.1681/ ASN.2008121270

34. Ghanassia E, Villon L, Thuan Dit Dieudonne JF, Boegner C, Avignon A, Sultan A. Long-term outcome and disability of diabetic patients hospitalized for diabetic foot ulcers: a 6.5-year follow-up study. Diabetes Care. 2008;31(7):1288-1292. doi:10.2337/dc07-2145

35. Orozco-Beltrán D, Navarro-Pérez J, Cebrián-Cuenca AM, et al. The influence of hemoglobin A1c levels on cardiovascular events and allcause mortality in people with diabetes over 70 years of age. A prospective study. Prim Care Diabetes. 2020;14(6):678-684. doi:10.1016/j.pcd.2020.06.003

36. Pilote L, Dasgupta K, Guru V, et al. A comprehensive view of sex-specific issues related to cardiovascular disease. CMAJ. 2007;176(6):S1-S44. doi:10.1503/cmaj.051455

37. Barton M. Cholesterol and atherosclerosis: modulation by oestrogen. Curr Opin Lipidol. 2013;24(3):214-220. doi:10.1097/ MOL.0b013e3283613a94

38. Coggins $\mathrm{CH}$, Breyer Lewis J, Caggiula AW, Castaldo LS, Klahr S, Wang SR. Differences between women and men with chronic renal disease. Nephrol Dial Transplant. 1998;13(6):1430-1437. doi:10.1093/ndt/13.6.1430

39. Aufhauser DD, Wang Z, Murken DR, et al. Improved renal ischemia tolerance in females influences kidney transplantation outcomes. J Clin Invest. 2016;126(5):1968-1977. doi:10.1172/JCI84712
International Journal of General Medicine

\section{Publish your work in this journal}

The International Journal of General Medicine is an international, peer-reviewed open-access journal that focuses on general and internal medicine, pathogenesis, epidemiology, diagnosis, monitoring and treatment protocols. The journal is characterized by the rapid reporting of reviews, original research and clinical studies across all disease areas. The manuscript management system is completely online and includes a very quick and fair peer-review system, which is all easy to use. Visit http://www.dovepress.com/ testimonials.php to read real quotes from published authors. 